\title{
Case report of a cervical myelomalacia caused by a thoracolumbar intradural disc herniation leading to intracranial hypotension
}

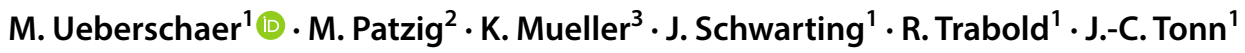

Received: 3 September 2020 / Revised: 24 September 2020 / Accepted: 25 September 2020 / Published online: 3 October 2020

(c) The Author(s) 2020

\begin{abstract}
A 50-year-old patient was admitted with symptoms of intracranial hypotension. MRI revealed a cervical myelomalacia caused by engorged epidural veins leading to a stenosis of the spinal canal. This condition is rarely described in patients with hydrocephalus and ventricular shunts suffering from chronic overdrainage. However, the reason in this patient was a CSF leak caused by an intradural disc herniation at T12/L1. After surgery, symptoms resolved and the cervical myelomalacia and the swollen epidural veins disappeared on postoperative MRI.In patients with engorged cervical epidural veins without a ventricular shunt, a CSF leak has to be considered.
\end{abstract}

Keywords Case report · Intradural disc herniation · Intracranial hypotension $\cdot$ Myelomalacia $\cdot$ CSF leak

\section{Introduction}

Intradural disc herniation (IDH) is a rare entity accounting for $0.26-0.3 \%$ of all disc herniations $[1,4,7]$. They typically occur at the lower lumbar spine (92\%) and are usually associated with neurological deteriorations and/or local pain $[3,6,7,8,12]$. Here, we present the case of a 50-year-old patient who was admitted merely with orthostatic headache due to a CSF leak caused by an IDH at the level of T12/L1 with radiological signs of a cervical myelomalacia caused by an engorged epidural venous plexus.

\section{Results}

\section{Patient Information and clinical findings}

A 50-year-old female patient was admitted with a 7-week history of postural headache deteriorating in upright position

M. Ueberschaer

moritz.ueberschaer@med.uni-muenchen.de

1 Department of Neurosurgery, University Hospital, LMU Munich, Marchioninistr. 15, 81377 Munich, Germany

2 Institute of Neuroradiology, University Hospital, LMU Munich, Munich, Germany

3 Department of Neurology, University Hospital, LMU Munich, Munich, Germany accompanied by nausea and vomiting. At neurological examination, she presented without any pathological findings, especially no symptoms of lumbar nerve root compression. The medical history of the athletic patient revealed no relevant previous disease or trauma.

\section{Diagnostic assessment}

Cranial magnetic resonance imaging (MRI) disclosed bilateral subdural hygromas typical for intracranial hypotension (Fig. 1). MRI of the cervical spine showed massively engorged epidural veins leading to a severe stenosis of the spinal canal with concurrent signs of myelomalacia at C3 (Fig. 2a, b). MRI of the lumbar spine presented a prominent disc spur at the level of T12/L1. Additional CT-myelography revealed a CSF leakage at the right ventral circumference of the dural sac correlating with the herniated disc (Fig. 3).

\section{Clinical course}

Initial treatment with caffeine did not lead to an improvement of the symptoms. A lumbar puncture with injection of a blood patch was not performed due to the bilateral hygromas. Therefore, surgery was indicated.

After microsurgical right-sided fenestration at the level T12/L1, the herniated disc spur was identified perforating the posterior longitudinal ligament and the dura with pronounced CSF leakage. The spur was carefully detached 

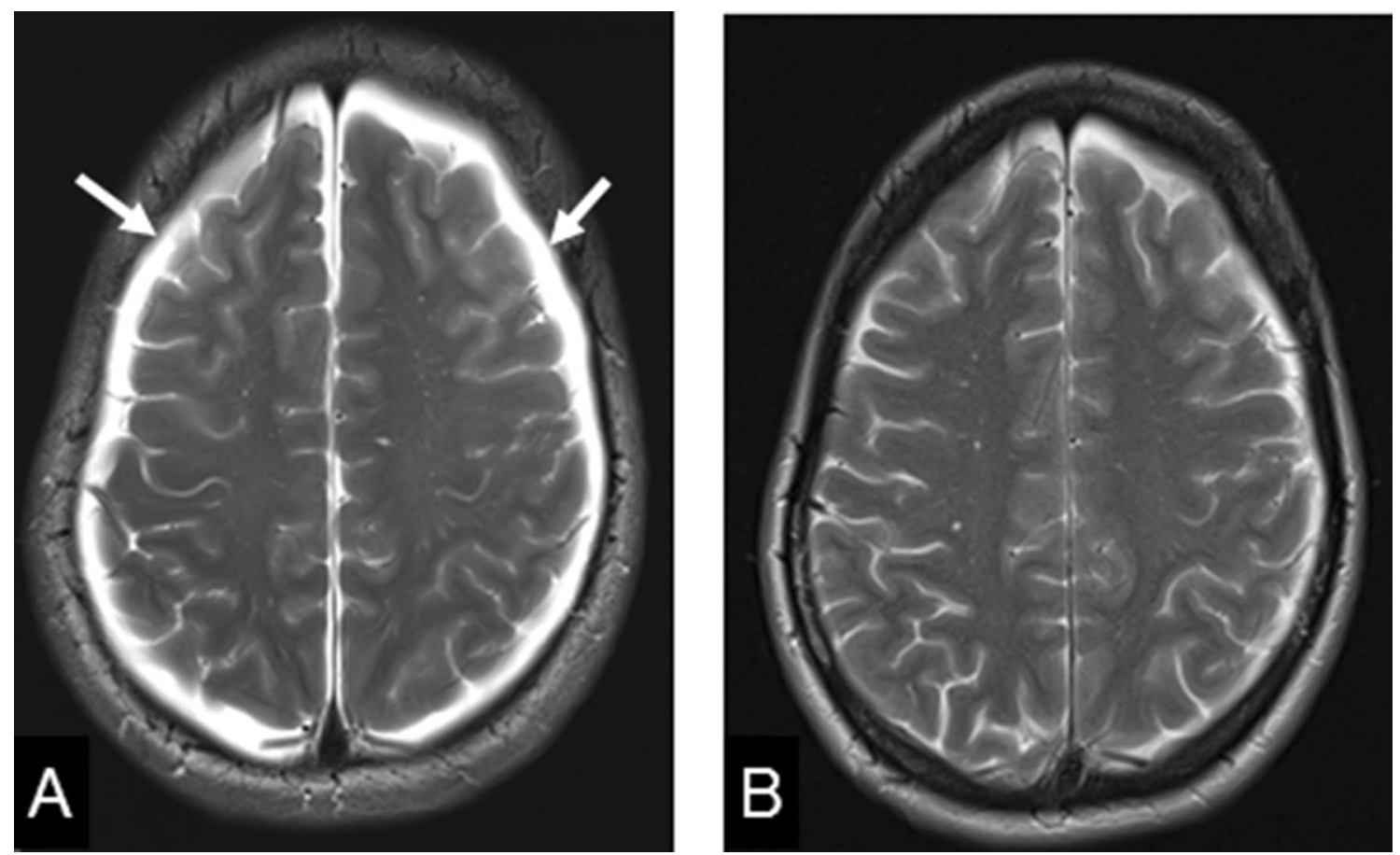

Fig. 1 a Bilateral subdural hygromas in T2 weighted MRI (arrow); b significantly improved hygromas according to postoperative MRI

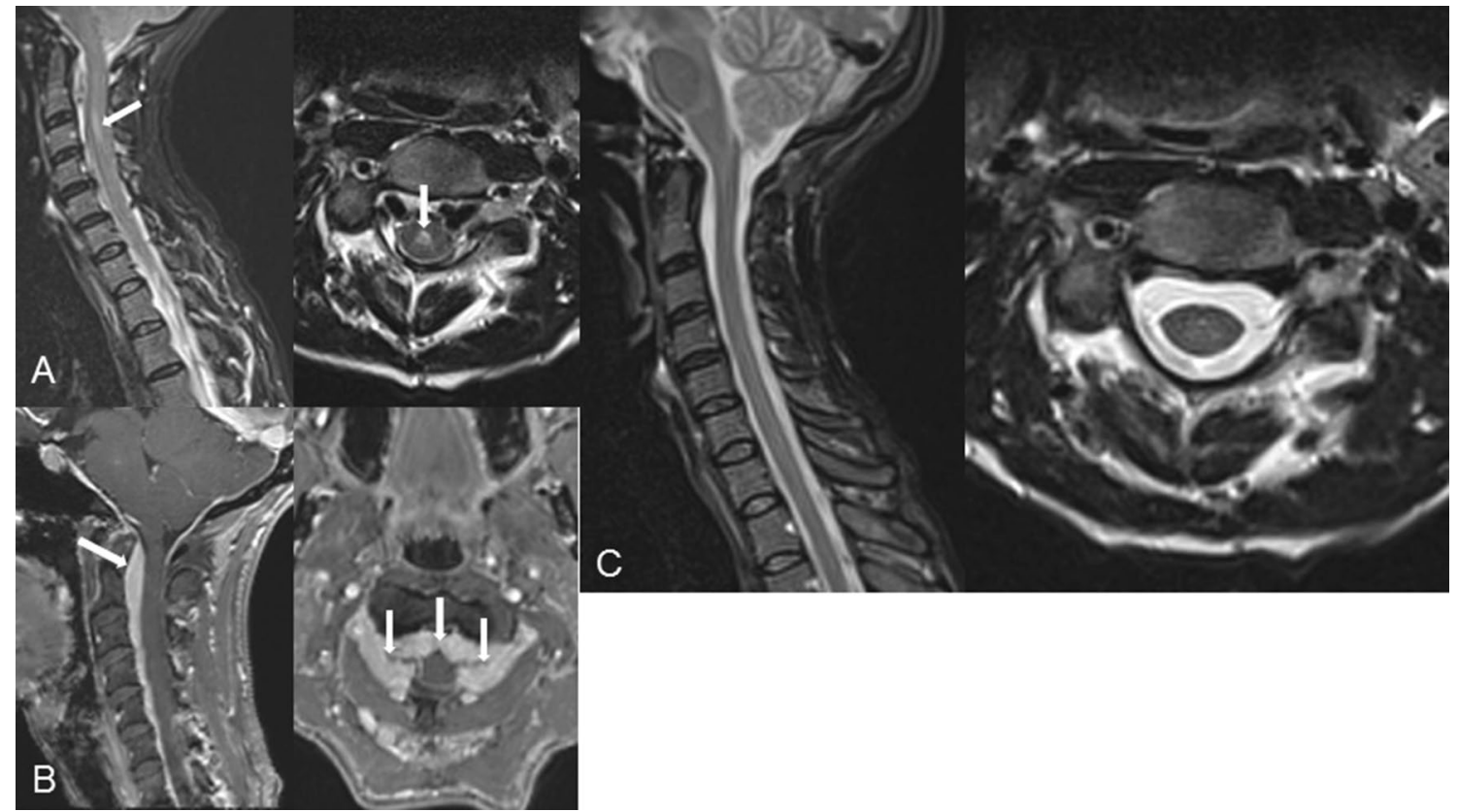

Fig. 2 a Preoperative myelomalacia (arrows) at C3 in sagittal STIRsequences and axial T2 weighted MRI; b Preoperative CE-MRI showing the prominent epidural veins leading to a spinal cord com-

from the dural sack under the microscope. After removal, the dural defect was sutured and secured with a fibrin sponge pression (arrows); c Normal epidural space without evidence of persisting myelomalacia at $\mathrm{C} 3$ according to the sagittal postoperative STIR- and axial T2 weighted MRI

(Tachosil ${ }^{\circledR}$ ) (Fig. 4). After bed rest for $72 \mathrm{~h}$, the headache resolved completely. 


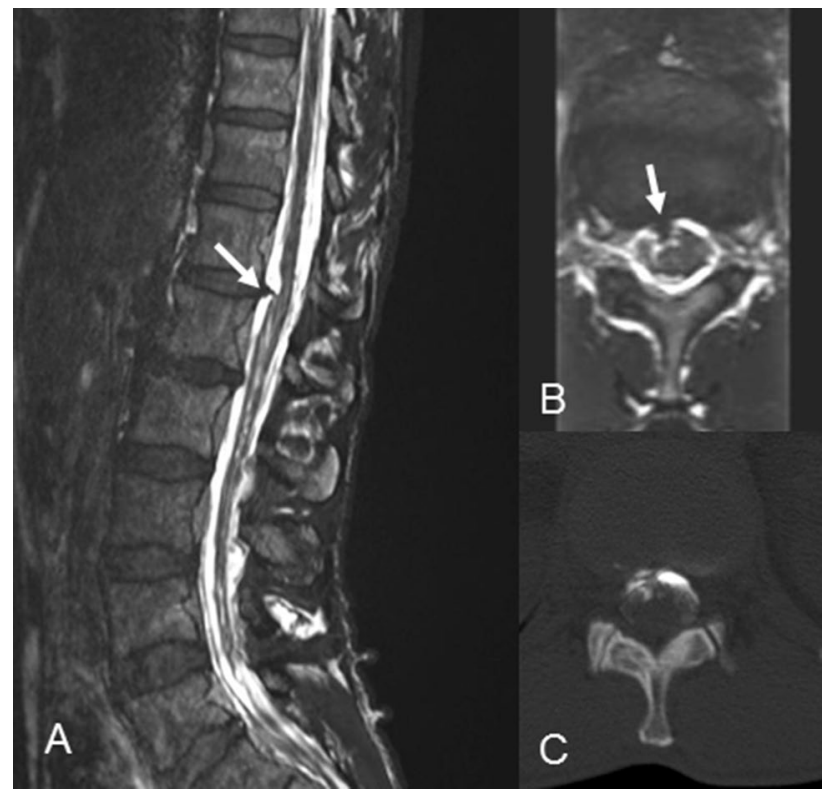

Fig. 3 a, b Sagittal and axial CISS MRI shows the discogenic spur at T12/L1(arrow); c CT-myelography with epidural contrast-pooling and right-sided ventromedial contrast agent extravasation

MRI 3 days after surgery showed resolution of both the hygroma and the myelomalacia at $\mathrm{C} 3$. The width of the cervical epidural space returned to normal due to the regression of the engorged peridural veins (Fig. 2c).

Histopathological examination confirmed a partially calcified disc herniation.

The patient was discharged at day 5 after the surgery without postural headaches or any neurological deficits. At the 3-month follow-up, the patient still had no orthostatic headache and the cranial MRI as well as the MRI of the cervical spine showed no pathological findings.

\section{Discussion}

Regarding the surgical procedure, resection of the herniated disc and suture of the dural leakage were feasible via an interlaminary fenestration and a more invasive transdural approach could be avoided. The intraoperative finding matched with the report of Beck et al. who identified discogenic microspurs as origin for a majority of CSF leaks in their case series [2].

In addition to the scant literature describing intracranial hypotension caused by an IDH [5], our case additionally presented a cervical myelomalacia at the level of $\mathrm{C} 3$ caused by an engorged epidural venous plexus. This rare phenomenon has been observed in intracranial hypotension caused by chronic overdrainage in patients with hydrocephalus and ventricular shunts [9, 10, 13-15]. In these cases, a mechanism is assumed which leads to an imbalance of intracranial fluids [14]. In accordance to the Monro-Kellie hypothesis, the total volume of intracranial blood, CSF and brain tissue remains constant. Any reduction of one of these components leads to an excess of one or more of the other components [11]. In our patient, the reduction of CSF volume and pressure caused an increase of the intravasal blood volume (the brain tissue volume remaining constant). The increased intracranial blood volume in this instance mainly affects the venous system with subsequent rise of the venous pressure leading also to an engorgement of the blood volume in the epidural venous plexus of the cervical spine. The dilation of the veins not only compensates the lack of CSF volume, but also leads to a compression of the spinal cord. The dilation of the veins is, thus, at the expense of the volume of the spinal cord explaining the spinal cord edema. Such a condition, previously reported in the context of intracranial hypotension, has never been described in a patient with CSF leak caused by a herniated disc. The fact that both headache and
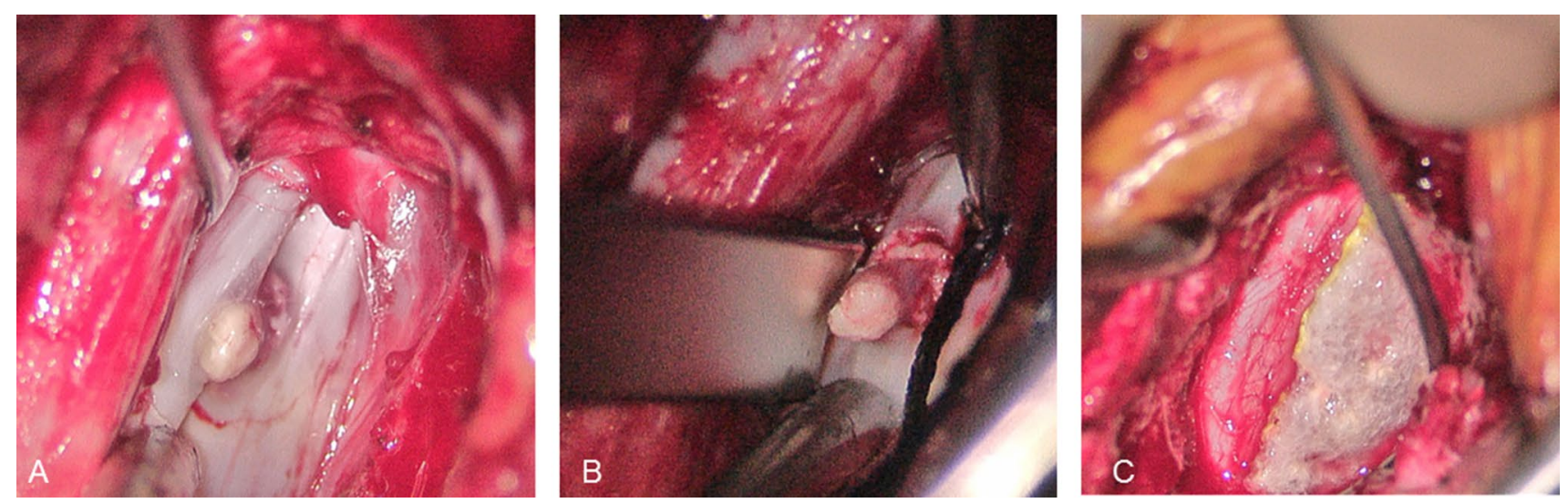

Fig. 4 a Discogenic spur perforating the dural sac; $\mathbf{b}$ the spur after seperation from the dura; $\mathbf{c}$ final result after dural suture and application of a fibrin sponge (Tachosil) 
radiological signs of myelomalacia with engorged epidural veins resolved immediately and concomitantly after closure of the CSF leak underlines this concept of pathophysiology.

Although patients usually have orthostatic headaches that primarily lead to diagnosis, CSF leakage must be considered in patients with swollen epidural veins of the cervical spine without a ventricular shunt. Dilation of the venous plexus appears to cause potential damage due to the continuous compression of the spinal cord according to MRI. The absence of pain and neurological deficits does not rule out a disc herniation as the underlying cause.

Funding Open Access funding enabled and organized by Projekt DEAL.

\section{Compliance with ethical standards}

Conflicts of interest There is no conflict of interest with any of the authors.

Informed consent The patient has consented to the submission of the case report for submission to the journal.

Open Access This article is licensed under a Creative Commons Attribution 4.0 International License, which permits use, sharing, adaptation, distribution and reproduction in any medium or format, as long as you give appropriate credit to the original author(s) and the source, provide a link to the Creative Commons licence, and indicate if changes were made. The images or other third party material in this article are included in the article's Creative Commons licence, unless indicated otherwise in a credit line to the material. If material is not included in the article's Creative Commons licence and your intended use is not permitted by statutory regulation or exceeds the permitted use, you will need to obtain permission directly from the copyright holder. To view a copy of this licence, visit http://creativecommons.org/licenses/by/4.0/.

\section{References}

1. Barbanera A, Serchi E, Fiorenza V, Nina P, Andreoli A (2009) Giant calcified thoracic herniated disc: considerations aiming a proper surgical strategy. J Neurosurg Sci 53:19-25 (discussion 25-16)

2. Beck J, Ulrich CT, Fung C, Fichtner J, Seidel K, Fiechter M, Hsieh K, Murek M, Bervini D, Meier N, Mono ML, Mordasini P, Hewer E, Z'Graggen WJ, Gralla J, Raabe A (2016) Diskogenic microspurs as a major cause of intractable spontaneous intracranial hypotension. Neurology 87:1220-1226. https://doi.org/10.1212/ WNL.0000000000003122
3. D’Andrea G, Trillo G, Roperto R, Celli P, Orlando ER, Ferrante L (2004) Intradural lumbar disc herniations: the role of MRI in preoperative diagnosis and review of the literature. Neurosurg Rev 27:75-80. https://doi.org/10.1007/s10143-003-0296-3(discussion 81-72)

4. Epstein NE, Syrquin MS, Epstein JA, Decker RE (1990) Intradural disc herniations in the cervical, thoracic, and lumbar spine: report of three cases and review of the literature. J Spinal Disord 3:396-403

5. Fiechter M, Ott A, Beck J, Weyerbrock A, Fournier JY (2019) Intradural non-calcified thoracic disc herniation causing spontaneous intracranial hypotension: a case report. BMC Surg 19:66. https://doi.org/10.1186/s12893-019-0527-3

6. Fiorenza V, Ascanio F, Di Lorenzo I (2020) Clinicopathologic features of thoraco-lumbar interdural disc herniations. A retrospective case series with a systematic literature review. World Neurosurg. https://doi.org/10.1016/j.wneu.2020.04.015

7. Floeth F, Herdmann J (2012) Chronic dura erosion and intradural lumbar disc herniation: $\mathrm{CT}$ and MR imaging and intraoperative photographs of a transdural sequestrectomy. Eur Spine J 21(Suppl 4):S453-457. https://doi.org/10.1007/s00586-011-2073-2

8. Han IH, Kim KS, Jin BH (2009) Intradural lumbar disc herniations associated with epidural adhesion: report of two cases. $\mathbf{J}$ Korean Neurosurg Soc 46:168-171. https://doi.org/10.3340/ jkns.2009.46.2.168

9. Ho JM, Law HY, Yuen SC, Yam KY (2016) Overshunting-associated myelopathy: report of 2 cases. Neurosurg Focus 41:E16. https://doi.org/10.3171/2016.7.FOCUS16179

10. Liu JK, Gottfried ON, Brockmeyer DL (2006) Epidural venous engorgement resulting in progressive cervical myelopathy from shunt-related intracranial hypotension. case report and review of the literature. J Neurosurg 105:499-503. https://doi.org/10.3171/ ped.2006.105.6.499

11. Mokri B (2001) The Monro-Kellie hypothesis: applications in CSF volume depletion. Neurology 56:1746-1748. https://doi. org/10.1212/wnl.56.12.1746

12. Ponzo G, Furnari M, Umana GE, Giuffrida M, Nicoletti GF, Scalia G (2020) Intradural lumbar disc herniations at the L1-L2 level: a case study and literature review. Surg Neurol Int 11:67. https:// doi.org/10.25259/SNI_108_2020

13. Ulrich NH, Maier M, Bernays RL, Krayenbuhl N, Kollias S (2013) Cervical myelopathy due to chronic overshunting in a pediatric patient: case report and review of the literature. Turk Neurosurg 23:410-414. https://doi.org/10.5137/1019-5149.JTN.5604-11.0

14. Wolfe SQ, Bhatia S, Green B, Ragheb J (2007) Engorged epidural venous plexus and cervical myelopathy due to cerebrospinal fluid overdrainage: a rare complication of ventricular shunts. Case Report. J Neurosurg 106:227-231. https://doi.org/10.3171/ ped.2007.106.3.227

15. Yousry I, Forderreuther S, Moriggl B, Holtmannspotter M, Naidich TP, Straube A, Yousry TA (2001) Cervical MR imaging in postural headache: MR signs and pathophysiological implications. AJNR Am J Neuroradiol 22:1239-1250 